\title{
The Plan-Do-Check-Act Cycle of Value Addition
}

\section{Gidey $E^{*}$, Jilcha K, Beshah B and Kitaw D}

School of Mechanical and Industrial Engineering, Industrial Engineering Chair, Addis Ababa Institute of Technology, Addis Ababa University, Addis Ababa, Ethiopia

\begin{abstract}
Value addition has only been measured as the difference between output and input prices and the critical roles of all functions in the process of value addition were not clearly known. Moreover, some core functions that inherently exist in the process of value addition were ignored until recently. The process of value addition and enhancement is continuous in its approach. Despite the fact that the value addition process is a continuous process, only its absolute measures were used for evaluating the intensity of value addition. Usually, value addition to a product was considered to happen only in the shop floor. In reality however, value addition is not only the responsibility of manufacturing function; rather, other functions before and after manufacturing also add significant tangible or intangible value to a product. The continuous characteristics of the value addition process can be visualized and evaluated in terms of the PDCA continuous process cycle so that value addition can be enhanced in a continuous basis. The PDCA cycle is a renowned continuous quality improvement approach and has been widely used by many successful companies as a strategic weapon for enhancing organizational performance. Hence, this paper roots its core idea towards the conceptual design of continuous value addition process using the PDCA cycle. The study also intends to identify the potential functions that were ignored and their respective roles. Thus, six core functions in the value addition process are identified and categorized into the four distinct phases of the PDCA cycle. The findings of this paper will, at large, help academicians and practitioners care for the respective roles of functions in the process of value addition and easily know how these functions interact in a continuous basis.
\end{abstract}

Keywords: Value; Value addition; Function; Innovation; PDCA Cycle; Process; Manufacturing

\section{Introduction}

Customers of recent times demand products and services to have the maximum added value. They are not willing to pay for products that pass through wasteful processes. In this regard, the norm 'value addition' has become a reference for expressing the performance of organizations. However, it was loosely treated and expressed as the difference between output and input prices. But, many intangible inputs might be ignored. In value addition calculations, those inputs that are consumed only in the production process were considered. But, value chain related studies revealed that there are additional functions beyond manufacturing [1].

More than $90 \%$ of manufacturing activities are non-value adding of which, $65 \%$ are not necessary at all. Only less than $10 \%$ of manufacturing activities are thought to add value that customers need [2-4]. Continuous improvement efforts have only been targeted towards enhancing value by eliminating wastes. Such continuous processes have mainly been described by and enclosed within the Plan-Do-Check-Act (PDCA) domain $[5,6]$. This cycle has also been known as Deming cycle or Shewhart's cycle. The PDCA cycle has been a foundation for process improvement its central theme being enhancing value in a way that customers' specifications are

Regularly captured and improved. PDCA has been practiced as a main competitive advantage and continuous problem solving approach by many successful companies all over the world.

Problems are identified and prioritized to be addressed. Solution approaches are generated and the best is selected and implemented; products and processes are checked for whether they incorporated the proposed improvement; and lastly, decisions are made regarding the effectiveness of the improvements introduced. Then, new improvement ideas are generated and forwarded to be further considered in next iteration. This process never ends; and lasts in the lifetime of companies. However, it usually is limited within the shop floor and design function; this process hardly gives indications for what functions exist in the process of value addition and enhancement. It also ignores the immediate consideration of customer requirements and feedback. For example, in continuous improvement initiatives, the intangible benefits that marketing function contributed in enhancing value addition into products was hardly considered.

If companies fail to consider the corrections requested by their customers on time, there would be a high probability for such companies to incur high cost and extinct shortly. Companies are recently obliged to dominate their competitors by exceeding both customers' requirements and competitors' capabilities. Thus, companies are urged to have strong research and innovation function as part of their system than ever. Every new innovation and improvement made on a product need to be standardized so that consumers will be confident on it. Thus, standardization inherently adds value to a product which was previously unnoticed; the cost and benefits of standardization has little been considered in the continuous quality improvement of products.

Value was traditionally considered to be added only in the manufacturing; functions before and after it, have been overlooked. This paper is therefore an attempt to extend the concept of continuous process improvement beyond the manufacturing environment in a way that the value added into a product would be reviewed. Moreover, the PDCA cycle would come across for improvement, not only based on problem identification process but also based on the rationale flow

*Corresponding author: Gidey E, School of Mechanical and Industrial Engineering, Industrial Engineering Chair, Addis Ababa Institute of Technology, Addis Ababa University, Addis Ababa, Ethiopia, Tel: +251-111232414, +251911002935; E-mail: ephyalem2007@yahoo.com

Received December 30, 2013; Accepted February 19, 2014; Published February 25, 2014

Citation: Gidey E, Jilcha K, Beshah B, Kitaw D (2014) The Plan-Do-Check-Act Cycle of Value Addition. Ind Eng Manage 3: 124. doi: 10.4172/2169-0316.1000124

Copyright: ( 2014 Gidey E, et al. This is an open-access article distributed under the terms of the Creative Commons Attribution License, which permits unrestricted use, distribution, and reproduction in any medium, provided the original author and source are credited. 
of value from its conception till its delivery to the customer. Thus, the continuity of value addition and improvement can preferably be analyzed using the PDCA cycle when a product passes through all value adding functions.

\section{Literature Review}

Recently, the leading competitive advantage of companies is exceeding customers' requirements. In their way of exceeding customers, companies are also urged to establish research and innovation functions [7]. The phrase 'value addition' has been used to express the extent of capturing and exceeding customers' requirements. Usually, customers will to buy products which give them the ultimate function at the minimum cost possible. All activities in the long way towards serving the customer should by any means be accepted by the customer. Customers are not willing to pay for products and services that pass through wasteful processes; the existence of waste benefits neither the customer nor the provider. A product passes through many functions before it reaches the customer. Plenty of methods have been devised which help to streamline processes and eliminate unnecessary activities and to enhance value addition. According to Dong-Young et al. [5], Quality Management is a holistic philosophy that fosters all functions of an organization through continual organizational change. It involves an ongoing refinements and structural problemsolving in response to continuous feedback from customers so as to link organizational efforts to innovation [8]. Innovation refers to new applications of knowledge, ideas, methods, and skills that can generate unique capabilities and leverage an organization's competitiveness [9].

In all of these cases, improvements gains have been interpreted into value addition. Until recently, the shop floor was the main concern to evaluate the extent of value addition into products. However, compared to the needs of recent customers, the value addition into a product is no more the only issue of shop floors; rather, customers' can mainly be exceeded through research and innovation both by continuously

\begin{tabular}{|c|c|}
\hline $\begin{array}{l}\text { Plan } \\
\text { - Create appropriate teams } \\
\text { - Gather all available data } \\
\text { - Understand customers' needs } \\
\text { - Describe the process that surrounds the } \\
\text { problem } \\
\text { - Determine root cause(s) } \\
\text { - Design action plan } \\
\text { - Develop plan }\end{array}$ & $\begin{array}{l}\text { Do } \\
\text { - Implement improvement } \\
\text { - Collect appropriate data } \\
\text { - Measure progress } \\
\text { - Document results }\end{array}$ \\
\hline $\begin{array}{l}\text { Check } \\
\text { - Summarize and analyze data } \\
\text { - Evaluate results relative to targets \& see } \\
\text { differences } \\
\text { - Review any problems/errors } \\
\text { - Record what was learned } \\
\text { - Specify any remaining issues or unintended } \\
\text { costs }\end{array}$ & $\begin{array}{l}\text { Act } \\
\text { - Standardize desired } \\
\text { improvements } \\
\text { - Formalize "current best } \\
\text { approach } \\
\text { - Communicate results broadly } \\
\text { - Identify next improvement }\end{array}$ \\
\hline
\end{tabular}

Table 1: Important characteristics and contents of the four stages of PDCA cycle. studying what the customer really wants and by minimizing wasteful manufacturing activities [3,4,10-12]. According to European Commission report on Key Enabling Technologies [13], state-of-theart philosophies for eliminating wastes are results of tedious research and innovation from both the academics and industry. Reducing or eliminating organizational wastes and other problems have been approached through the Deming's or Shewhart's PDCA cycle [14]. It is known as an iterative four-step management approach used for controlling and continuously improving processes and products $[6,12]$.

Richard et al. [15] have tried to show the detailed activities of each stage of the PDCA cycle the central theme being increasing customer satisfaction (Table 1).

Though the basic theme indicated in Table1 is customer satisfaction, what's embodied within the stages is the value addition process. Each stage contributes to the overall value added into the product/service. Of course, PDCA has got enormous applications: as a model for continuous improvement; when starting a new improvement project; when developing a new or improved design of a process; when defining a repetitive work process; and when implementing any change [1].

Robert et al. [12] in his paper entitled 'From continuous improvement to continuous innovation', generated an accelerated PDCA which was thought to be suitable for dynamic environments. His model outweighs the conventional PDCA in that he under weights Plan and overweighs Do. Recently however, as a result of the tough competition among competitors and the dynamically changing customer needs, companies have no option than continuously improving their processes and overall performances which lastly should result in delighting customers $[6,9,16]$.

This paper targets to study the benefits out of PDCA by using it as a model for accelerated continuous improvement when defining a repetitive work process. It is therefore an attempt to model a comprehensive continuous value addition process model which encompasses external functions and expressed in terms of the functions involved in it using the PDCA cycle as a framework. The seemingly repetitive continuous process improvement is extended by incorporating external functions which were previously ignored in the value addition process. The new model will devise a new outlook of value addition as well as functional interaction in the value addition process.

\section{Identification of Functions in the Value Addition Process}

Here, logical justifications are presented and dealt in detail so that the value addition process can be continuously improved by making use of the PDCA cycle. It theoretically examines the content of product value addition at its different stages. In this regard, the value addition process is divided into three consecutive phases as shown in Figure 1. Each phase will have value adding functions for value addition; and the content of value addition by respective functions would then be

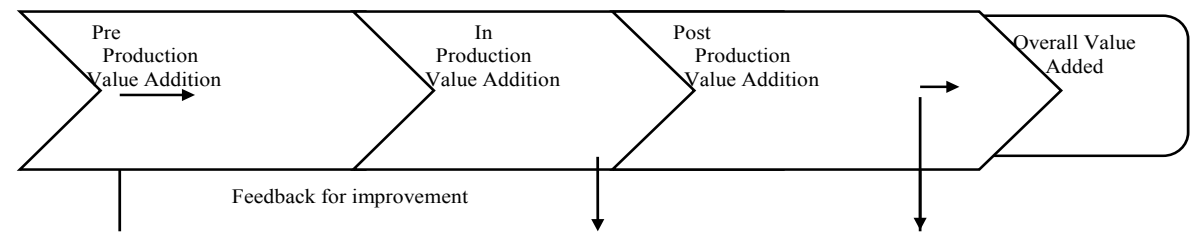

Figure 1: Three distinct phases of product value addition evolution. 
identified through the PDCA cycle. Hence, the research approach followed in this paper is an exploratory content analysis using the PDCA method of continuous improvement (Figure 1).

Three distinct phases of product value addition evolution though most products have common features that all customers want, today's tough competition obliged producers to continuously search for improvements and additional new features. Mostly, customer requirements, company capabilities, competition scenarios, and new features are captured and considered mainly in the early stages of a product's value addition process. Consistent with the dynamically changing customer requirements and with the 'quality at source' notion of Lean Manufacturing, products' quality should be considered and designed at the very beginning of the value addition process. But, Lean Manufacturing limited the 'quality at source' concept within a company - in the design function. Recent customers, however, want updated and innovation built-in products. And, when firms get into the global market they might encounter tough competition to win.

Inherently and practically, the first function that captures customers' requirements is the research and innovation function. Especially those high-tech companies are expected to have a sophisticated and wellestablished research and innovation center. Likewise, other companies are also urged to have such facilities which can help them continuously consider the dynamically changing customers' requirements. The innovative power found within a company is also a deciding factor for success in gaining market acceptance [16] the Design function. This starts with defining the detailed technical requirement of the new product or improvements identified to be incorporated in an existing one. Such activities still add value to the product in way that the innovations and standards begin to be interpreted and converted into suitable manufacturing details. Of course, there are occasions whereby both innovation and design functions are merged into Research and Design function. Therefore, Innovation and Design functions are categorized as the 'Pre-production' portion of the value addition process. All product details are planned and documented through these two functions. Clearly, input information is required from the other parts of the value addition process and the output of this function is sent to subsequent functions found in the 'In-production' part of the process.

Physical transformation of value is predominantly accomplished through Manufacturing, Assembly \& Packaging functions. This constitutes enormous useful interactions among different entities such as men, machines, materials, and methods. Product values proposed in previous functions are physically realized into tangible objects. Conventionally, these functions have been considered as the only functions to add value into products. Moreover, the packaging of products is also becoming another focus area to attract more customers. Recent customers also give attention not only on the functional value of products but also on the way the product is packed. Packaging is then thought to add a different perspective of value to the customer in a way that attractive packaging approaches that impress customers are introduced. Thus, Manufacturing, Assembly \& Packaging belong to the 'In-production' portion of the value addition process. What has been previously planned is practically realized through these functions.

Completed products need to be checked for their quality compared to what the customer previously stated. This functional requirement is basically practiced through quality control and inspection. This function adds a different perspective of value to the customer in a way that whether customers' requirements are met is checked. Those products which conform to customers' requirements should be standardized.
The notion of standardization came to lead in contributing value to products. Standards become norms and values that producers all over the world can smoothly communicate with customers. Standardization is therefore becoming a competitive advantage for today's companies. Had there been no standardization, one can imagine the confusion, instability, and crisis that might have been created in the world. Waste and variation, which majorly are affecting quality of products and customers satisfaction, are measured by taking these standards as nominal values. To this end, standardization can be considered as the gravitational force of value addition that kept markets in their stable position. But, in value addition determinations, the costs associated with and the benefits attained from standardization were yet unnoticed. Lastly, finished and quality products have to be marketed. Most organizations actively strive to promote their products so as to increase their market shares. As a result, the functions in the 'Post-production' portion of the value addition process include: Quality control \& inspection, Standardization, and Marketing.

\section{Outlining the PDCA Cycle of Value Addition}

As specified in previous deliberations, this paper is an attempt to devise a continuous value addition framework which incorporates previously unnoticed functions using the PDCA cycle. The functions in the three phases of value addition are already identified; these are:

- Pre-production: innovation and design

- In-production: manufacturing, assembly, and packaging

- Post-production: quality control \& inspection, standardization, and marketing

Then, this session investigates the position of the functions in the PDCA cycle through logical rationales. Even in the 'quality at source' view point, value addition process starts at the design phase; it neglects the outbound functions in the value addition process. Customers usually want products with high value but less cost. In order to continuously improve products' value, recent literatures advised that companies need to give higher attention to innovation since recent customers are observed to demand products with innovated values. It is also thought that companies in the developed economies compete on innovation and companies in developing economies compete in poor labor market and add little value to final products. The Design function is thought to be the innovative power of companies since all the innovations already generated should be made into suitable media such as engineering drawings for product and process design and product portfolio development. In these two functions, the required value is conceptualized and prerequisites to realize that intended value are set. These two functions involve innovative ideas and cumulatively help to plan values that customers want to get; otherwise, the successive functions are largely unable to realize the true value.

Conceptual value addition requirements are then sent to the Manufacturing and/or Assembly functions to be physically realized. Significant portion of the value that was anticipated in the Innovation and Design functions is practically realized at this portion of the value addition process. It's not doubtful that these two functions perform physical transformation of value. Packaging finished products can also be considered as part of the value addition process. Though packaging practically adds no value into the product, recent customers' first impression is being laying not only on product's quality but also on its package. The impression that the packaging material and approach creates should be valued as far as it satisfies customers. Packaging system is recently one of the areas that have got priority to exceed customers' 
expectations even when little improvements are made on the basic product itself. Hence, the Manufacturing \& Assembly and Packaging functions make the 'Do' stage of the continuous value addition cycle.

Next, the function, quality control \& inspection, helps not to send a defective product to the customer; this may, in a long-term, affect customers' satisfaction and producer competition. In this function, adequate sample products are taken and checked for their quality. Nowa-days, manufacturers are not the core decision makers in the process of value addition into products; rather, customers get the key role in deciding the content and extent of value addition. Completed products should then be sent to the customer. Organizations actively strive to promote their products so as to increase their market shares. In doing so, companies promote the value of the functions they offer and the unique features that their products constitute. Products have to be marketed and shipped properly and safely. It would not be nonsense to say marketing is the key function that sustains a firm. Promoting ones product or service using appropriate media helps customers know more and more about the product/service they intend to buy. Moreover, existing customers feel proud when they heard about a product they most liked.

Likewise, when new or improved products are introduced, standardization becomes a main focus and competitive advantage in the process of value addition whereby producers and consumers all over the world can communicate. This is a value adding function which is practiced mostly but overlooked to add value into a product. Not only products require standardization, but also processes and systems through which products pass through. Also, whenever a new product enters the market or improvements are made on it, it should be standardized so that variability will be reduced and uniformity of outputs can be kept for long. Therefore, standardization might either be required at the initial stage of a newly introduced product or at the last stage of improved products. Consequently, the three functions in the 'Post-production' portion of the value addition process are: Quality control \& inspection, Standardization, and Marketing in which the first belongs to the 'Check' stage of the PDCA cycle and the other two belong to the 'Act' stage of the cycle. From these founding deliberations, a PDCA-based framework of value addition process is proposed in terms of the associated functions (Figure 2).

\section{Discussion}

Here, it should be noted that the proposed functions and the


Figure 2: The PDCA cycle for value addition framework for their interconnectedness and cyclic appearance do inherently exist. But, some of the functions were overemphasized for the value they add to a product and benefits that can be attained out of their cyclic appearance have not been valued yet. The paper extends the value adding functions beyond the boundaries of manufacturing with intent. Though the activities of the design function has been considered in the value addition process, the extent of the value it adds was not as such comparable to manufacturing and assembly functions. This paper noticed that appreciable part of a product's value is enacted through design and innovation. Continuous improvement movements require intensive research and innovation in every aspect; let alone being in an era of exceeding customers' expectation, companies in the mass production era had been greatly supported by innovative ideas and products. Every customer requirement should be properly captured in a cost effective manner; this needs innovative mind set. Consequently, innovation and design together build up the 'Plan' stage of the PDCAbased value addition cycle (Figure 2).

Until recently, quality-related philosophies emphasized on the minimization of wastes and variations; customer-focus; leadership; process-based; employees involvement, and continuous improvement. Especially, the involvement of all employees is basically targeted towards utilizing their innovative mind set in problem solving requirements. Employees may also have the chance to hear the voice in their social interactions and can actively participate in decision making processes. Lean Manufacturing theories indicated that more than $90 \%$ of the manufacturing activities are non-value adding activities. It's also known that customers do not need to pay for these non-value adding activities. Besides, the two functions, manufacturing and assembly, make up the 'Do' stage of the value addition cycle since the conceptual value proposed by the previous functions is practically realized through these functions. These two internal functions were known to add almost all of products' value. This paper noticed that majority of the value that has been thought to be added through these two functions is really added in the previous functions-design and innovation.

Products produced in the shop floor should be checked for their quality; products that constitute less value than what has been proposed or less than what the customer really wants. This is basically performed through the quality control and inspection function. This function belongs to the 'Check' stage of the PDCA-based value addition cycle. Protecting the customer from receiving substandard products seemed to add no value to the product; but, this activity is not, by any means, a non-value adding activity. It adds an indirect value by keeping the balance of customers' satisfaction and by keeping the reputability of the product's future market. This would then be assumed as a function in the post-production phase of the value addition process. The quality control and inspection activities in the intermediate manufacturing processes are assumed to be part of the manufacturing function. Lastly, improved and satisfactorily produced products should be standardized and marketed on time.

\section{Summary and Conclusion}

The aim of the study was to visualize and evaluate the value addition process as a continuous process using the four stages of PDCA cycle and identify the core functions that the literature dropped out from consideration in the value addition process. The paper has revealed that manufacturing is not the only function that adds value in the value addition process. It exceptionally considers additional functions that were previously forgotten in value addition premises. Especially, innovation and standardization were not recognized for their 
contribution in value addition. This paper however realizes that these two functions contribute important but intangible values to products.

Overall, six core functions are identified and constituted in the value addition process; these are: innovation, design, manufacturing, quality control \& packaging, logistics, marketing, and standardization. As a result, in a pre-production phase, Innovation and Design functions help organizations to plan what a value to add and how to realize it. The two core functions found in the production phase, Manufacturing \& Assembly and Packaging, have infrastructures to realize the value addition proposed by the previous functions - Innovation and Design. After production, whether products are according to customers' requirements are checked by the Quality control \& inspection function. Lastly, two core functions are identified for taking two basic actions - scrutinizing improvements and delivering quality. Standardization is identified as an action to concretize the improvements made into products and Marketing is considered as an action to deliver completed and quality products to customers. In this manner, the paper offers pertinent rationales for the notion that all functions that exist in the process of value addition, more or less, tangibly or intangibly, add value to the final product.

In order to devise a framework for continuous analysis and improvement of the value addition process, the PDCA cycle has been introduced and all identified functions are categorized into the four distinct phases of the cycle - Plan-Do-Check-Act. Thus, innovation and design functions are planning activities that conceptually depict what customers require and what a value to add into the final product. The conceptually innovated and designed value is physically realized by the manufacturing and assembly functions. Aesthetical values are also added through the packing function. Since these functions have physical contact with the product, they are grouped in the 'Do' phase of the continuous value addition cycle. All processes could not completely give products that the customers need. In this regard, higher care is made to protect opportunities of sending defectives to customers. This would then be the 'Check' phase of PDCA cycle for value addition. Eventually, conforming products need to be commercialized improvements introduced into products and processes need to be standardized. These two functions collectively construct the 'Act' phase of PDCA value addition cycle since these two functions are actions that companies communicate with their customers.

In this regard, this paper extends the value addition process one level before and after the manufacturing function. It also extends the 'Quality at Source' notion beyond the traditional limit at the design function. This finding will, at large, help academics and practitioners to attentively look for the respective roles of the functions in the process of value addition and easily know how they should interact in a continuous basis. Further study is required to estimate the real measure of value added by respective functions in producing practical items.

\section{References}

1. Zokaei AK, Simons DW (2006) Value chain analysis in consumer focus improvement: A case study of the UK red meat industry. The International Journal of Logistics Management 17: 141-162.
2. Hayes RH, Pisano GP (1994) Beyond world-class: The New Manufacturing Strategy. Harvard Business Review: 77-86.

3. Shah R, Ward PT (2003) Lean manufacturing: context, practice bundles, and performance. J OperManag 21: 129-149.

4. Womack JP, Jones DT (1996) Lean Thinking: Banish Waste and Create Wealth in Your Corporation. New York: Simon \& Schuster, USA.

5. Kim DY, Kumar V, Kumar U (2012) Relationship between quality management practices and innovation. J Oper Manag 30: 295-315.

6. Olson W (2006) Systems Thinking, Sustainability Science and Engineering Defining principles. Elsevier: Technology \& Engineering, USA.

7. Ralph K (1997) The Human Side of Managing Technological Innovation: A Collection of Readings Oxford University Press, USA.

8. Ralph K, Allen TJ (1984) Organizational Issues in the Introduction of New Technologies.Cambridge, Mass: Ballinger, USA.

9. Andersson M, Lindgren R, Henfridsson O (2008) Architectural knowledge in inter-organizational IT innovation. J Strategic Inf Syst 17: 19-38.

10. David WC, Abraham S (2008) Using value-chain analysis to discover customers strategic needs. Journal of Strategy \& Leadership36: 29-39.

11. Salvendy G (2001) Handbook of Industrial Engineering: Technology and Operations Management, $3^{\text {rd }}$ Ed., John Wiley \& Sons, Inc, USA.

12. Richard A, Reid, Koljonen EL, Bruce BJ (1999) The Deming Cycle Provides a framework for Managing Environmentally Responsible Process Improvements. Quality Engineering 12: 199-209.

13. European Commission (2011) High-Level Expert Group on: Key Enabling Technologies. Final Report.

14. Marrs FO, Mundt BM (2001) Enterprise Concept: Business Modeling Analysis and Design.the Handbook of Industrial Engineering. ( $3^{\text {rd }}$ Edn), John Wiley \& Sons, Inc, USA.

15. Robert EC (2002) From continuous improvement to continuous innovation Total Qual Manage 13: 1051-1056.

16. Krause FL, Mertins K, Heisign P, Hoffmann I, Helmke M (2001) Computer Integrated Technologies and Knowledge Management. The Handbook of Industrial Engineering. ( ${ }^{\text {rd }}$ Edn), John Wiley \& Sons, Inc, USA. 